4. Belicova, A., Ebringer, L., Krajcovic, J., Hromadkova, Z., and Ebringerova, A., Antimutagenic effect of heteroxilans, arabinogalactans. pectins and mannans in the euglena assay, World J. Microbiol. Biotechnol., 2001, vol. 17, no. 3, pp. $293-299$.

5. Grieshop, S.M., Flickinger, E.A., and Eahey, G.C., Oral administration of Arabinogalactan affects immune status and fecal microbial populations in dogs, J. Nutr., 2002, vol. 132, no. 3, pp. 478-482.

6. Robinson, R.R., Causey, J., and Slavin, J.L., Nutritional Benefits of Larch Arabinogalactan, McCleary, B.V. and Prosky, L., Eds., Oxford, UK: Blackvvell Science, 2001, pp. 443-451.

7. Robinson, R.R., Feirtag, J., and Slavin, J.L., Effects of dietary arabinogalactan on gastrointestinal and blood parameters in healthy human subjects, J. Am. Coll. Nutr., 2001, vol. 20, no. 4, pp. 279-285.

8. Medvedeva, E.N., Babkin, V.A., and Ostroukhova, V.A., Larch arabinogalactan--properties and prospects for the use (review), Khim. Rastit. Syr'ya, 2003, no. 1, pp. 27-37.

UDC 616.441-007.5-089 DOI 10.22448/AMJ.2017.3.79-80

\title{
RESULTS OF SURGICAL TREATMENT OF NODULAR GOITER IN THE REGION OF ENDEMIC GOITER
}

\section{N.P. Volodchenko, N.V. Valova, V.V. Ishchenko, Kravtsova S.V, Shevcheko E.A., Ishchenko T.K}

Amur State Medical Academy, CAPHD AR “Blagoveshchensk City Clinical Hospital”. Blagoveshchensk, Russia

Nodular goiter is the main pathology of the thyroid gland and ranges from $42 \%$ up to $98 \%$ in endemic regions of Russia $(2,3,4)$. The wide prevalence of nodular pathology of the thyroid gland sometimes causes considerable difficulties in choosing the optimal method of treatment and the volume of surgical intervention. Despite the large experience of surgical treatment of nodular goiter, the number of postoperative complications is $7-8 \%$, the frequency of postoperative relapse does not decrease and reaches $0,5 \%-12 \%(1,2,3,4)$.

The purpose of the research: to study the results of surgical treatment of patients with nodular thyroid formations.

Material and methods The results of operative treatment of 112 patients with nodular formations of the thyroid gland, operated in the city clinical hospital, are analyzed. There were 109 women $(97.3 \%)$ and $3(2.7 \%)$ men, aged 23 up to 76 years old. The diagnostic algorithm included: analysis of clinical symptoms, assessment of the history of the disease, clinical and biochemical blood tests, assessment of thyroid hormone function (study of TTG, T4 (free), T3 in blood serum), ultrasound and thyroid TAB. Indications for surgery were: large sizes of nodes, causing neck deformation and cervical compression syndrome, signs of malignant growth, retrosternal site of the nodes, relapse of the disease. All patients were operated under anesthesia. The amount of surgical intervention depended on the nature of the pathological process.

Distribution of patients depending on the volume of the operation

\begin{tabular}{|ll|}
\hline Type of operation & Number of transactions \\
\hline Hemithyroidectomy (GE) & $32(28,6 \%)$ \\
\hline Thyroidectomy(FC) & $41(36,6 \%)$ \\
\hline Subtotal resection (CP) & $39(34,8 \%)$ \\
\hline Total & $112(100 \%)$ \\
\hline
\end{tabular}

Results and discussion

Early postoperative complications were observed in 7 (6.3\%) patients, in 3 patients - unilateral and in 1 - bilateral damage of recurrent nerves, in 3 - transient hypoparathyroidism and in 1 - suppuration of the operating wound. As a rule, a multidisciplinary approach was used to treat complications. Histological examination of resected thyroid tissue was dominated by nodular colloid goiter in 79 patients $(71.5 \%)$, nodal toxic goiter was detected in 11 ones (9.7\%), autoimmune thyroiditis in $9(7.9 \%)$, adenomas in $5(4.4 \%)$, cancer in 8 persons (7\%). Long-term results of treatment were studied in $78(69.6 \%)$ patients in the period from 1 up to 5 years. In 17 patients $(21.7 \%)$ relapses of nodal formations were detected in the 1-st year after the operation, in 1-3 years in 15 patients (19.2\%), and in later terms in $11(14.1 \%)$ patients. Thus, in $32(41 \%)$ patients, the recurrence of the disease developed in the early period after surgical interventions. The most common cause of recurrence of goiter was the deficiencies committed during the operation (insufficient revision of the thyroid gland, abandonment of altered areas or small thyroid nodules, complication during surgery, which did not allow it to be completed radically). According to our data, the relapse of the disease developed more often after surgery for multinodular goiter and depended not on preoperative and intraoperative diagnosis of multinodular goiter forms, but on the volume of the operation. The majority of patients with relapse of nodular goiter (73\%) complained about the presence of nodal education on the neck;in one third there were noted difficulty of swallowing, shortness of breath, weakness, fatigue, drowsiness. All patients with recurrent goiter after the examination were repeatedly operated under general anesthesia. Operations with recurrent goiter are difficult. The amount of surgical intervention at recurrent goiter - removal of all available thyroid tissue.Hypoparathyroidism was detected in 1 of the patient (1.2\%), a retracted postoperative scar in 2 ones $(2.4 \%)$, hypothyroidism in $5(6.4 \%)$ patients. After surgical interventions for the thyroid gland pathology, all 
the patients were on the " $D$ " account of endocrinologists, received an adequate correction of occurred violations. Conclusions

1. Complex pre-operative examination of patients with nodular formations of the thyroid gland allows to assess correctly the nature of pathology and to perform an adequate surgical intervention.

2. The main causes of relapse and repeated operations are: inadequacy of the first operation, absence or non-usefulness of preventive therapy in the postoperative period, not elimination of primary pathogenetic factors.

3. All operated patients should be on the " $\mathrm{D}$ " account of the endocrinologist, which will allow to identify hormonal disorders and morphological changes in the "thyroid remainder" and make an adequate correction.

Bibliography

1. Petrov V.G., Makhnev A.V., Nelaeva A.A. Tactics of diagnosis and treatment of thyroid nodules. Problems of endocrinology. 2002. - V. 48, No. 5 - pp. 3-6.

2. Gorbachyova T.A., Petrov V.G., YasnovV.Yu. Features of anesthesia and complications in the surgical treatment of thyroid pathology // Tyumen Medical Journal. - 2004. - No.3-4. - pp.53-56.

3. Petrov V.G. The value of the size and growth rate of nodular thyroid gland formation in the prognosis of its belonging to oncopathology // Bulletin of the Tyumen University. - 2006. - No.5. - pp. 154-159.

4. Petrov V.G., Malinin D.I. Perfection of the technique of extrafascialhemithyroidectomy // Siberian Medical Journal. - 2007. No.2. - pp. 98-102.

5. Petrov V.G., Malinin D.I. Long-term results of surgical treatment of nodular goiter // Siberian Medical Journal. - 2007. - No.4 pp. 98-102.

\section{PHARMACOECONOMIC EVALUATION BASED ON META-ANALYSIS OF DOMESTIC AND IMPORTED CEFUROXIME SODIUM FOR BACTERIAL INFECTION}

\section{Wang Haiyan, Wang Ying}

Hei Longjiang University of Chinese Medicine, 24 He Ping Road, Xiang Fang District, Harbin, 150040, xiaohanyan@126.com

Hei Longjiang University of Chinese Medicine, 24 He Ping Road, Xiang Fang District, Harbin, 150040,wyviolin85@163. com

Objective: To assess the efficiency and safety of the domestic and imported cefuroxime sodium for bacterial infection, and then compare pharmacoeconomic evaluation of the two.

Methods: Collecting all clinical trials by retrieving Chinese Journal Full-text Database CNKI and Wanfang database on experiment of domestic and imported cefuroxime sodium in the treatment of bacterial infection, which are published during 2000 and 2010. The keywords are 'Domestic cefuroxime sodium', 'imported cefuroxime sodium' and 'bacterial infection'. The matching degree is fuzzy, then it appeared 48 papers. After choosing by person, there are 17 papers on domestic and imported cefuroxime sodium in the treatment of bacterial infection, in which, 11 articles met the inclusion criteria. All selected papers were randomized trial research. The papers about domestic and imported cefuroxime sodium in the treatment of bacterial infection, which are in accordance with inclusion criteria perform Meta analysis. And then take the total effective rate, bacterial eradication rates, adverse effect rates as an indicator to make pharmacoeconomic evaluation with the least cost method.

Results: A total of 11 RCTs and 873 patients were enrolled. The effective rate of domestic cefuroxime sodium and imported one is $[\mathrm{OR} 1.03,95 \% \mathrm{Cl}(0.66,1.61), \mathrm{P} 0.90]$, the bacterial eradication rates is $[\mathrm{OR} 0.78,95 \% \mathrm{Cl}(0.44,1.40), \mathrm{P} 0.40]$ and the adverse effect rates is $[\mathrm{OR} 0.95,95 \% \mathrm{Cl}(0.58$, 1.54), $P$ 0.83]. The minimum cost method shows that the imported cefuroxime sodium costs higher.

Conclusion: The currently available evidence shows that there are no significant difference of

the total effective rate, bacterial eradication rates and adverse effect rates between the domestic cefuroxime sodium and the imported one. And the economic value of domestic cefuroxime sodium is higher.

[Reference]

[1] Ochoa C, Eiros J M, Inglada L, et a1. Assessment of antibiotic prescription in acute respiratory infections in adult[J]. J Infect, 2000, 41(1): 73.

[2] Verheagan J, VerbistL. In-vitro activityof 21 beta-la-ctam antibiotics against penicillin-susceptible and penicillin resistant Streptococcus pneumoniae[J]. J Antimicrob Chemother, 1998, 41(3): 381.

[3] Scott L J, Ormrod D, Goa K J. Cefuroxime axetil: An updated review of its use in the management of bacterialinfections[J]. Drugs, 2001, 61(10): 1455.

[4] He Ping, Zhng Xuezhen, Zhang Yujie, et al. The Clinical Research on Domestic and Imported Cefotaxime Sodium in the Treat- 